American Journal of Applied Sciences 8 (10): 1027-1031, 2011

ISSN 1546-9239

(C) 2011 Science Publications

\title{
Static Var Compensator based on Fuzzy Logic Control for Damping Power System Oscillation
}

\author{
Prechanon Kumkratug \\ Department of Electrical Engineering, \\ Faculty of Engineering at Si Racha, \\ Kasetsart University, 199 M. 6, Tungsukhla, \\ Si Racha, Chonburi, 20230, Thailand
}

\begin{abstract}
Problem statement: The disturbance in power system is unavoidable situation. It causes in power system oscillation. Approach: This study applied the Static Var Compensator (SVC) to damp power system oscillation. The fuzzy logic control is applied to determine the control strategy of SVC. The simulation results are tested on a Single Machine Infinite bus. The proposed method is equipped in sample system with disturbance. The generator rotor angle curve of the system without and with a SVC is plotted and compared. Results: It was found that the system without a SVC has high variation whereas that of the system with a SVC has much smaller variation. Conclusion: From the simulation results, the SVC can damp power system oscillation.
\end{abstract}

Key words: Power system, system oscillation, fuzzy logic control, phase shifter, thyristor controller, series capacitor, static synchronous compensator, static synchronous, series compensator

\section{INTRODUCTION}

The continuously growing demand for electric power requires transmitting larger amounts of power transfer without building new transmission line. With the increased loading in modern power system, power system is getting risk. The blackout occurred in North American in 2003 challenges power engineering to find the new method for enhancing dynamic performance of power system. Flexible AC Transmission System (FACTS) controllers, based on the rapid development of power electronics technology, have been proposed for power flow control in steady state and dynamic state. The various forms of FACTS devices are the Static Var Compensator (SVC), Thyristor Controlled Phase Shifter Transformer (TCPST), Thyristor Controller Series Capacitor (TCSC), Static Synchronous Compensator (STATCOM), Static Synchronous Series Compensator (SSSC), Unified Power Flow Controller (UPFC) and Inter-line Power Flow Controller (IPFC) (Magaji and Mustafa, 2009; Kumkratug, 2010; Taher et al., 2008; Rudez and Mihalic, 2009).

The control strategy of FACTS devices plays an important role for effective improvement of dynamic performance of a power system. Many research used in linear control schemes of SVC for this purposes. However, modern power system is a large and complex network and disturbances usually cause in nonlinear (Ahmad and Mohamed, 2009; Hafaifa et al., 2009; Amir et al., 2010; Mustafa and Magaji, 2009; Majee and Roy, 2010; Zacharie, 2009; Bagher et al., 2009; Chamsai et al., 2010).

This study presents the control strategy of a SVC for improving power system dynamic performance. The concept of fuzzy logic control is applied to derive control of SVC. The control strategy is then applied to a SVC placed in a power system to investigate the improvement of the power system dynamic performance.

\section{MATERIALS AND METHODS}

Mathematical model: Consider a single machine infinite bus system is equipped with a SVC at bus $\mathrm{m}$ as shown in Fig. 1a. The dynamics of the machine, in classical model, can be expressed by the following differential Eq. 1 and 2:

$\delta=\omega$ 


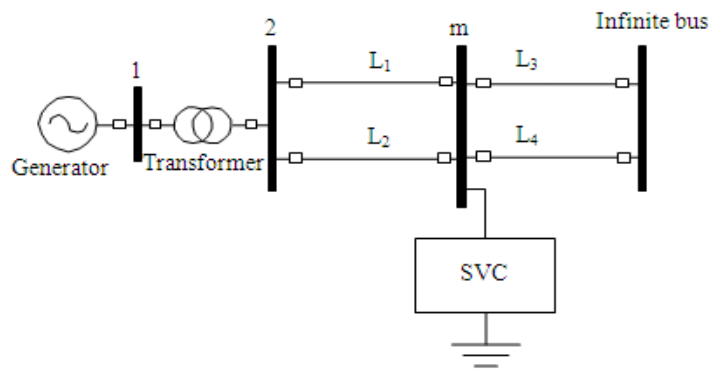

(a)

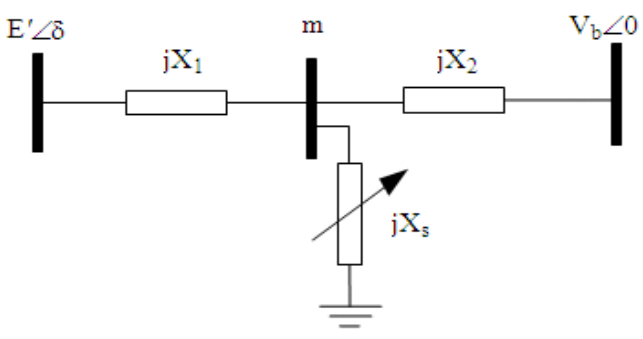

(b)

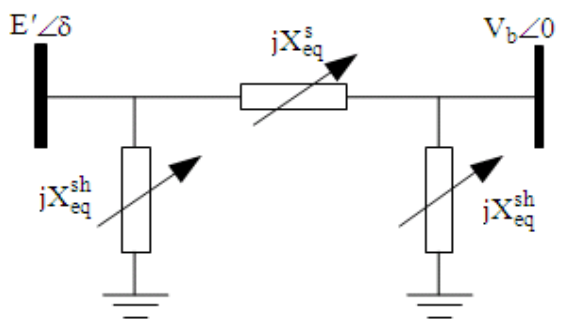

(c)

Fig. 1: A Single Machine Infinite Bus (SMIB) system (a) single line diagram (b) Equivalent circuit of system with SVC (c) Equivalent circuit after star-delta transformation

$\dot{\omega}=\frac{1}{\mathrm{M}}\left[\mathrm{P}_{\mathrm{m}}-\mathrm{P}_{\mathrm{e}}^{\mathrm{sh}}\right]$

Here, $\delta, \omega, \mathrm{P}_{\mathrm{m}}$ and $\mathrm{M}$ are the rotor angle, speed, input mechanical power and moment of inertia, respectively, of the machine. $\mathrm{P}_{\mathrm{e}}^{\text {sh }}$ is output electrical power of machine with the SVC. Without the SVC, the electrical output power of the machine $\left(\mathrm{P}_{\mathrm{e} 0}\right)$ can be expressed as Eq. 3:

$\mathrm{P}_{\mathrm{eo}}=\mathrm{E}^{\prime} \mathrm{V}_{\mathrm{b}} \mathrm{B}_{\mathrm{o}} \sin \delta$

Here:

$\mathrm{E}^{\prime}$ and $\mathrm{V}_{\mathrm{b}}=$ The machine voltage behind transient reactance and infinite bus voltage, respectively

$\mathrm{B}_{\mathrm{o}}=$ The transfer susceptance between the machine internal bus and the infinite bus
The transfer susceptance is given by Eq. 4:

$\mathrm{B}_{\mathrm{o}}=\frac{1}{\mathrm{X}_{1}+\mathrm{X}_{2}}$

Here:

$X_{1}=$ The sum of the machine transient reactance and transformer leakage reactance

$\mathrm{X}_{2}=$ The equivalent reactance of the lines between bus $\mathrm{m}$ and the infinite bus

Thus without a SVC, the system dynamic equation, in general form, can be written as Eq. 5:

$\mathrm{x}=\mathrm{f}_{0}(\mathrm{x})$

Where:

$$
\mathrm{x}=\left[\begin{array}{l}
\mathrm{x}_{1} \\
\mathrm{x}_{2}
\end{array}\right]=\left[\begin{array}{l}
\delta \\
\omega
\end{array}\right]
$$

And:

$$
f_{0}(x)=\left[\begin{array}{l}
f_{01}(x) \\
f_{02}(x)
\end{array}\right]=\left[\begin{array}{c}
\omega \\
\frac{P_{m}-P_{e 0}}{M}
\end{array}\right]
$$

When a SVC is placed at bus $m$, it can be represented by a variable shunt reactance $X_{s}$ (or susceptance $B_{s}$ ) between bus $m$ and ground as shown in Fig. 1b. By using star-delta transformation, Fig. 1b can be represented by its equivalent circuit as shown in Fig. 1c. In Fig. 1c, the electrical output power of the machine has no effect on the shunt reactances $X_{10}$ and $X_{20}$. However, the output power of the machine, for a given $E^{\prime}$ and $V_{b}$, depends on the transfer reactance $X_{\text {eq }}$. The value of the transfer reactance is given by Eq. 6 :

$X_{e q}=X_{1}+X_{2}+\frac{X_{1} X_{2}}{X_{s}}$

Thus with the SVC, the electrical output power $\left(\mathrm{P}_{\mathrm{es}}\right)$ of the machine can be expressed as Eq. 7:

$\mathrm{P}_{\mathrm{e}}^{\mathrm{sh}}=\mathrm{E}_{\mathrm{q}}^{\prime} \mathrm{V}_{\mathrm{b}} \mathrm{B}_{\mathrm{eq}} \sin \delta$

Here $B_{\text {eq }}=1 / X_{\text {eq }}$. By using Eq. 4 and $6, B_{\text {eq }}$ can be written as Eq. 8:

$$
\mathrm{B}_{\mathrm{eq}}=\mathrm{B}_{0}(1+\mathrm{u})
$$

Where:

$$
\mathrm{u}=\left[\frac{\mathrm{B}_{\mathrm{s}}}{\mathrm{B}_{12}+\mathrm{B}_{\mathrm{s}}}\right] \text { and } \mathrm{B}_{12}=\left[\frac{\mathrm{X}_{1}+\mathrm{X}_{2}}{\mathrm{X}_{1} \mathrm{X}_{2}}\right]
$$




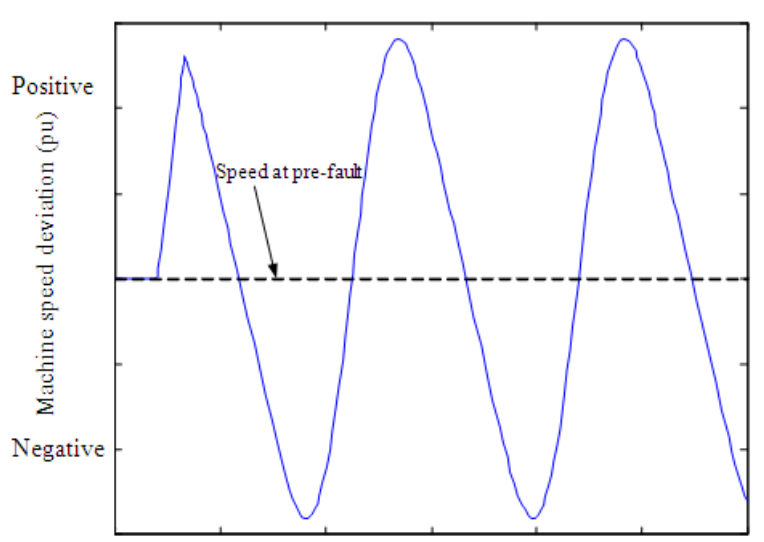

Fig. 2: Machine speed of system after disturbance

Thus the electrical output power of the machine with a SVC, becomes Eq. 9:

$\mathrm{P}_{\mathrm{e}}^{\mathrm{sh}}=\mathrm{P}_{\mathrm{e} 0}+\mathrm{uP}_{\mathrm{e} 0}$

From (1), (2) and (9) Thus with the SVC, the dynamic equations of the machine can be written as Eq. 10:

$\dot{\mathrm{x}}=\mathrm{f}(\mathrm{x}, \mathrm{u})=\mathrm{f}_{0}(\mathrm{x})+\mathrm{uf}_{1}(\mathrm{x})$

Where:

$$
f_{1}(x)=\left[\begin{array}{c}
f_{11}(x) \\
f_{12}(x)
\end{array}\right]=\left[\begin{array}{c}
0 \\
\frac{P_{e 0}}{M}
\end{array}\right]
$$

Fuzzy logic control: Figure 2 shows the machine speed of system after disturbance. Figure 3 shows the input and the output fuzzy membership function, respectively.

The machine speed (Fig. 4) at pre-fault is considered as reference at zero value $(\omega=0)$. This study uses the rules based on human reasoning of Mamdani inference engine. Rules are defined as follows:

- If $\omega$ is positive big then $B_{\mathrm{svc}}$ is positive big

- If $\omega$ postive then $B_{s v c}$ is positive

- If $\omega$ zero then $B_{\text {svc }}$ is zero

- If $\omega$ negative then $B_{\mathrm{svc}}$ is negative

- If $\omega$ negative big then $B_{\mathrm{svc}}$ is negative big

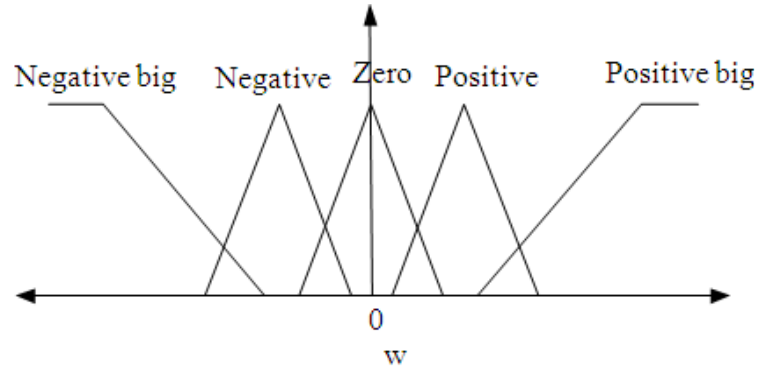

(a)

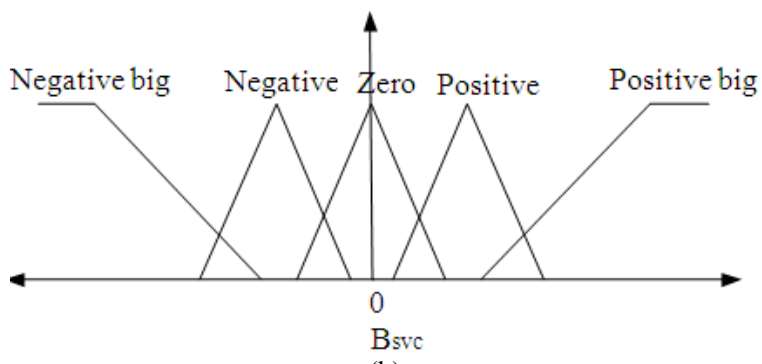

(b)

Fig. 3: Membership functions (a) input (b) output

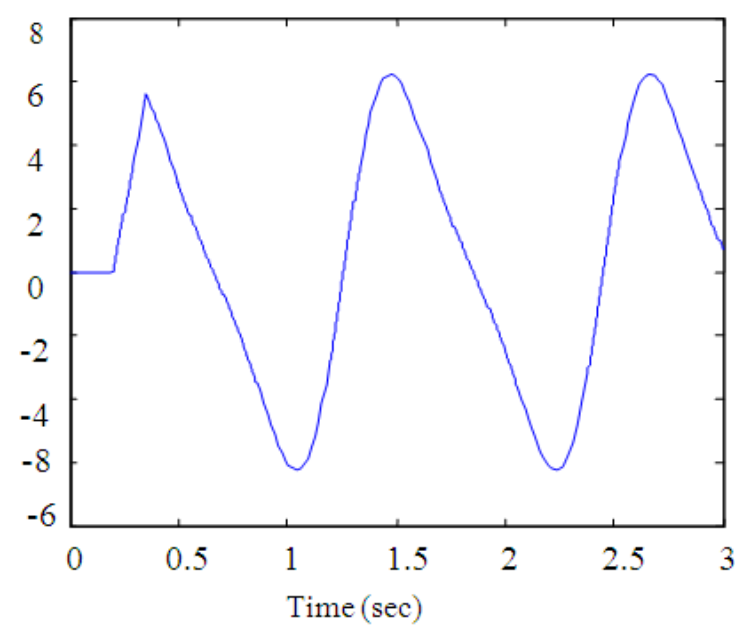

Fig. 4: Machine speed of sample system

\section{RESULTS}

The proposed control method is tested on sample system equipped with a SVC based fuzzy logic control strategy. The single line diagram of sample system is shown in Fig. 1a. The system parameters are:

$\mathrm{H}=6.5, \mathrm{X}_{\mathrm{t}}=0.1 \mathrm{pu}, \mathrm{X}_{\mathrm{d}}{ }_{\mathrm{d}}=0.3 \mathrm{pu}, \mathrm{X}_{\mathrm{L} 1}=0.4 \mathrm{pu}, \mathrm{X}_{\mathrm{L} 2}=0.4$ $\mathrm{pu}, \mathrm{X}_{\mathrm{L} 3}=0.4 \mathrm{pu}, \mathrm{X}_{\mathrm{L} 4}=0.4 \mathrm{pu}, \mathrm{P}_{\mathrm{m}}=1.0 \mathrm{pu}, \mathrm{E}_{\mathrm{q}}=1.23 \mathrm{pu}$ 


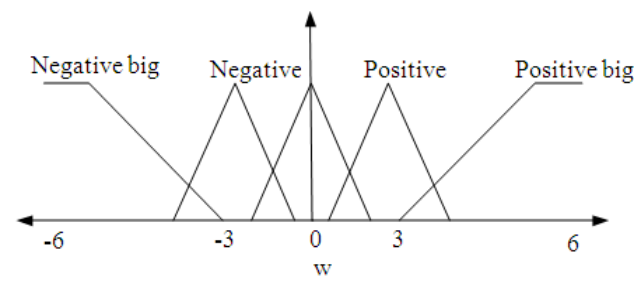

(a)

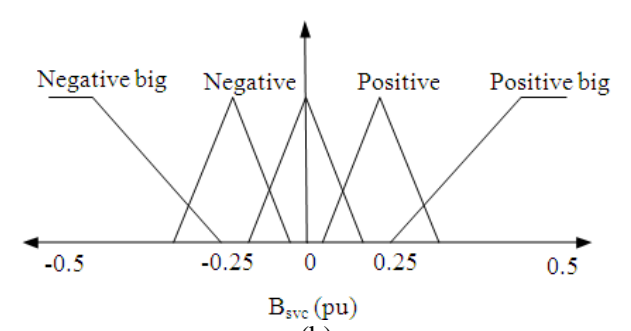

(b)

Fig. 5: Membership functions of fuzzy membership (a) Input (b) Output

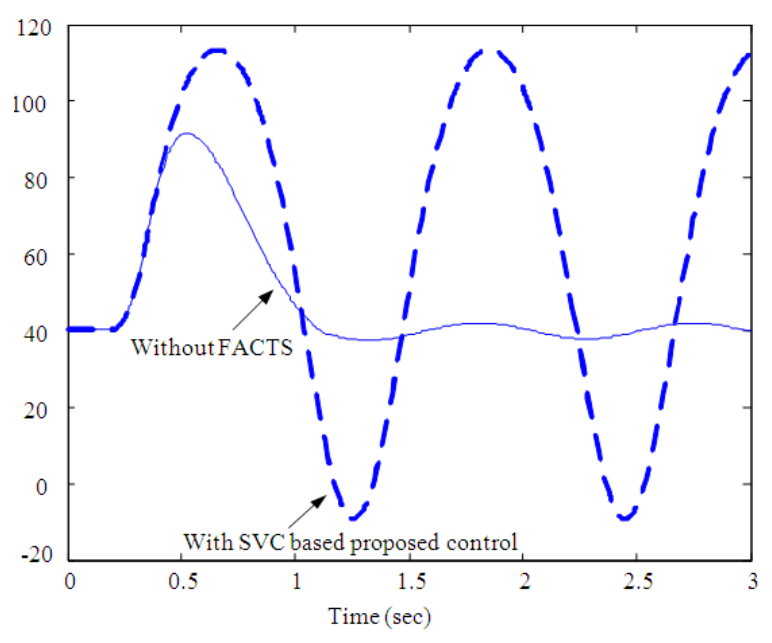

Fig. 5: Swing curve of the system without and with a SVC

It is considered that 3 phase fault appears at line 1 near bus $\mathrm{m}$ for $150 \mathrm{~ms}$ and then it is cleared by opening both circuit breakers. Figure 4 shows the machine speed of sample system without FACTS devices for generating the fuzzy membership of input $\omega$ and output $\mathrm{B}_{\mathrm{svc}}$ as shown in Fig. 5a and 5b, respectively. Figure 6 shows the swing curve of the system without and with a SVC.

\section{DISCUSSION}

It can be observed from the simulation results that the SVC based fuzzy logic control can improve power system oscillation. The maximum and minimum machine rotor angles are around 113.44 and -9.13, respectively. However, maximum and minimum machine rotor angles are improved to around 91.55 and 37.56 , respectively.

\section{CONCLUSION}

This study presented the method of improving power system oscillation using a SVC. The mathematical model of power system equipped with a SVC was systematically derived. It was found that a SVC affects on the line voltage. The dynamic performance of the power system can be controlled by a SVC. This study applied fuzzy logic control to determine the control law of SVC. The simulation results are tested on a sample system. From the simulation results, it indicates that a SVC based fuzzy logic control can improve the power system oscillation.

\section{REFERENCES}

Ahmad, M.A. and Z. Mohamed, 2009. Hybrid fuzzy logic control with input shaping for input tracking and sway suppression of a gantry crane system. Am. J. Eng. Applied Sci., 2: 241-251. DOI: 10.3844/ajeassp.2009.241.251

Bagher, M., B. Sharifian, M.R. Feyzi, S.H. Hosseini and R. Valinia, 2009. Implementing a vector controller using $68 \mathrm{k}$ processors. Am. J. Eng. Applied Sci., 2: 488-493. DOI: 10.3844/ajeassp.2009.488.493

Chamsai, T., P. Jirawattana and T. Radpukdee, 2010. Sliding mode control with PID tuning technique: An application to a DC servo motor position tracking control. Energy Res. J., 1: 55-61. DOI: 10.3844/erjsp.2010.55.61

Hafaifa, A., F. Laaouad and M. Guemana, 2009. A new engineering method for fuzzy reliability analysis of surge control in centrifugal compressor. American J. Eng. Applied Sci., 2: 676-682. DOI: 10.3844/ajeassp.2009.676.682

Kumkratug, P., 2010. Application of interline power flow controller to increase transient stability of power system. J. Comput. Sci., 6: 1490-1493. DOI: 10.3844 /jcssp.2010.1484.1487

Magaji, M. and M.W. Mustafa, 2009. Optimal thyristor control series capacitor neuro-controller for damping oscillations. J. Comput. Sci., 5: 980-987. DOI: $10.3844 /$ jcssp.2009.980.987

Majee, M.C. and A.B. Roy, 2010. Asymptotic behavior of an artificial neural network defined on multipartite directed graph. OnLine J. Biol. Sci., 10: 44-49. DOI: 10.3844/ojbsci.2010.44.49 
Mustafa, M.W. and N. Magaji, 2009. Optimal location of static var compensator device for damping oscillations. Am. J. Eng. Applied Sci., 2: 353-359. DOI: 10.3844/ajeassp.2009.353.359

Rudez, U. and R. Mihalic, 2009. Dynamic analysis of transition into island conditions of Slovenian power system applying underfrequency load shedding scheme. Proceedings of the IEEE Bucharest Power Tech Conference, Jun. 28-Jul. 2, IEEE Xplore Press, Bucharest, pp: 1-6. DOI: 10.1109/PTC.2009.5282175
Taher, S.A., R. Hematti, A. Abdolalipour and M. Nemati, 2008. Decentralized controller design for static synchronous compensator using robust quantitative feedback theory method. Am. J. Eng. Applied Sci., 1: 66-75. DOI: 10.3844/ajeassp.2008.66.75

Zacharie, M., 2009. Intelligent OkiKoSenPBX1 security patrol robot via network and map-based route planning. J. Comput. Sci., 5: 79-85. DOI: $10.3844 /$ jcssp.2009.79.85 